\title{
Degradation of Epichlorohydrin and Halohydrins by Bacterial Cultures Isolated from Freshwater Sediment
}

\author{
By ARJAN J. VAN DEN WIJNGAARD, DICK B. JANSSEN* AND \\ BERNARD WITHOLT \\ Department of Biochemistry, Groningen Biotechnology Centre, University of Groningen, \\ Nijenborgh 16, 9747 AG Groningen, The Netherlands
}

(Received 17 March 1989; accepted 24 April 1989)

\begin{abstract}
Three bacterial cultures, the Gram-negative strain AD1 and the Gram-positive strains AD2 and AD3, were isolated from freshwater sediment after enrichment with epichlorohydrin as sole carbon source. In batch cultures of strain AD1 and strain AD3, epichlorohydrin was rapidly degraded to 3-chloro-1,2-propanediol. Crude extracts of strain AD1 contained epoxide hydrolase activity towards epichlorohydrin, epibromohydrin, glycidol and propylene oxide as substrates. In contrast, strain AD2 did not actively convert epichlorohydrin but utilized 3-chloro-1,2-propanediol produced by slow chemical hydrolysis. No epichlorohydrin epoxide hydrolase was found in extracts of this organism. Crude extracts of strains AD1 and AD2 dehalogenated a number of mono- and dihalogenated alcohols and ketones, such as 1,3-dichloro2-propanol, 3-chloro-1,2-propanediol, 1-chloro-2-propanol, 1,3-dibromo-2-propanol, chloroacetone and 1,3-dichloroacetone. Dehalogenation yielded epoxides as products. The results suggest that epichlorohydrin is converted by strain AD1 via 3-chloro-1,2-propanediol and glycidol by the action of an epoxide hydrolase and a dehalogenase, respectively. The same route for dehalogenation proceeds in strain AD2, which, however, is dependent on chemical hydrolysis of epichlorohydrin rather than enzymic conversion.
\end{abstract}

\section{INTRODUCTION}

During recent years, much insight has been obtained into the aerobic biodegradation of chlorinated aliphatic hydrocarbons (for a review see Vogel et al., 1987). Relatively little is known about the microbial degradation of chlorinated aldehydes, alcohols and ethers, although several of them are important environmental pollutants (Ghisalba, 1983). Chloroethanol may serve as growth substrate for pure bacterial cultures and is degraded via chloroacetic acid (Stucki \& Leisinger, 1983). There are indications that bromoethanol, epichlorohydrin and chloroethylethers may be hydrolytically dehalogenated by bacterial dehalogenases (Janssen et al., 1988; D. B. Janssen, A. J. van den Wijngaard \& J. Prins, unpublished), although it is not clear whether the activities are involved in the utilization of these compounds. Enzymic formation of epoxides from halohydrins has been found in an organism that utilizes 2,3-dibromo-1-propanol (Castro \& Bartnicki, 1968; Bartnicki \& Castro, 1969).

Information is lacking on the bacterial degradation of halogenated epoxides, such as epichlorohydrin (3-chloro-1,2-epoxypropane) (Krijgsheld \& van der Gen, 1986). This compound is of great importance for chemical industries, where it is used for the production of glycerol and epoxy resins. Furthermore, it is an important starting material in the manufacture of a variety of surfactants, pharmaceuticals, insecticides, agricultural chemicals, coatings, adhesives, ionexchange resins, solvents and plasticizers (Krijgsheld \& van der Gen, 1986).

Epichlorohydrin was classified as a black list pollutant by the Commission of European Communities in 1982. The black list contains 129 substances that are cause for great concern in the protection of aquatic life (Krijgsheld \& van der Gen, 1986). Because of the toxic properties of 
epichlorohydrin and the lack of information on its biodegradation, we investigated whether bacterial utilization of this compound is possible, what organisms are involved and how degradation proceeds physiologically.

In this paper, three different bacterial cultures that are able to grow with epichlorohydrin as sole carbon source are described. The dehalogenation reactions were identified and a metabolic pathway for the biodegradation of epichlorohydrin is proposed.

\section{METHODS}

Organisms. Three different pure bacterial cultures, designated strain AD1, AD2 and AD3, were isolated from freshwater sediment that was polluted with chlorinated organics. Batch enrichments were carried out at $30^{\circ} \mathrm{C}$ in MMY-medium (see below) supplemented with $1 \mathrm{mM}$-epichlorohydrin as carbon source. The inoculum for the enrichment was $10 \%(\mathrm{v} / \mathrm{v})$ sediment. After several subcultivations in MMY-medium with $2.5 \mathrm{mM}$-epichlorohydrin, three pure isolates were obtained by repeated streakings on solid medium with $2.5 \mathrm{mM}$-epichlorohydrin as sole carbon source.

Spontaneous loss of the ability to grow on epichlorohydrin was observed for all three strains after two or more transfers on $0.8 \%$ nutrient broth agar. Therefore, the organisms were maintained on MMY-agar supplemented with epichlorohydrin. Epichlorohydrin-negative mutants of strain AD1 were isolated after several serial transfers in MMY-medium with $5 \mathrm{mM}$-glycidol as carbon source and maintained on glycidol-containing agar plates.

Media and growth conditions. The basal medium (MMY) that was used in all experiments contained $\left(1^{-1}\right): 5.37 \mathrm{~g}$ $\mathrm{Na}_{2} \mathrm{HPO}_{4} .12 \mathrm{H}_{2} \mathrm{O}, 1.36 \mathrm{~g} \mathrm{KH}_{2} \mathrm{PO}_{4}, 0.5 \mathrm{~g}\left(\mathrm{NH}_{4}\right)_{2} \mathrm{SO}_{4}, 0.2 \mathrm{~g} \mathrm{MgSO}_{4} .7 \mathrm{H}_{2} \mathrm{O}, 5 \mathrm{ml}$ trace metals solution (Janssen et al., 1985) and $10 \mathrm{mg}$ yeast extract (Difco laboratories). Cells were grown aerobically at $30^{\circ} \mathrm{C}$ under rotary shaking. To prevent evaporation of substrates, cultures were grown in closed serum flasks, filled to one-third of their volume with medium. The flasks were made gas-tight with screw caps containing Viton septa, which made it possible to sample cultures by a syringe, without loss of substrates. Carbon sources were added up to $5 \mathrm{~mm}$, if not stated otherwise, calculated as if the compounds added were completely dissolved in the water phase. All the halogenated compounds used were shown to be sterile. Serum flasks were closed immediately after addition of the compounds to prevent losses by evaporation. Inocula consisted of $5 \%(\mathrm{v} / \mathrm{v})$ of late exponential epichlorohydringrown cultures.

Growth was followed turbidimetrically at $450 \mathrm{~nm}$. Chloride levels in samples of culture fluids were determined with an ion-selective electrode (Orion type 94-17). Chloride levels in MMY-medium without halogenated substrate were less than $0.15 \mathrm{~mm}$.

Preparation of crude extracts. Cells were harvested from late exponential cultures by centrifugation (15 min, $10000 \mathrm{~g}$ ), washed once with $10 \mathrm{mM}$-Tris/ $\mathrm{H}_{2} \mathrm{SO}_{4}$ buffer, $\mathrm{pH} 7 \cdot 5$, containing $1 \mathrm{mM}$-EDTA and $1 \mathrm{mM}-\beta$-mercaptoethanol, and suspended in this buffer at $0^{\circ} \mathrm{C}$. In this way a cell suspension of $30-50 \mathrm{mg}$ dry wt ml ${ }^{-1}$ was obtained. After ultrasonic disruption of the ice-cold cells, a crude extract (10-15 $\mathrm{mg}^{-1}$ protein $\left.\mathrm{ml}^{-1}\right)$ was obtained by centrifugation ( $30 \mathrm{~min}, 40000 \mathrm{~g}, 4^{\circ} \mathrm{C}$ ).

Activities in crude extracts. Dehalogenase activities were assayed at $30^{\circ} \mathrm{C}$ in $50 \mathrm{~mm}$-Tris $/ \mathrm{H}_{2} \mathrm{SO}_{4}$ buffer, $\mathrm{pH} 7.5$, containing $5 \mathrm{~mm}$ substrate and crude extract in a final volume of $3 \mathrm{ml}$. Assays contained $10-60 \mathrm{mU}$ of enzyme $\mathrm{ml}^{-1}$. At different times, all within $25 \mathrm{~min}, 0.5 \mathrm{ml}$ samples were removed and assayed for halide levels by the colorimetric method of Bergmann \& Sanik (1957). The detection limit of this method was $0.05 \mathrm{~mm}$-chloride. Solutions of halogenated compounds used were prepared immediately before use. Chemical halide production was tested for all halogenated compounds used, and only found in controls with 1-bromo-2-propanol (initial velocity $\left.2.5 \times 10^{-3} \mathrm{mM} \mathrm{min}^{-1}\right), 1,3$-dibromo-2-propanol $\left(1.0 \times 10^{-2} \mathrm{mM} \mathrm{min}^{-1}\right)$ and 1,3-dichloroacetone $\left(1.2 \times 10^{-2} \mathrm{mM}\right.$ $\left.\min ^{-1}\right)$. For the calculation of enzyme activities, chemical halide production was subtracted from total halide production. One unit of enzyme activity was defined as the amount of enzyme that catalyses the formation of $1 \mu$ mol halide $\min ^{-1}$.

Epoxide hydrolase activities were assayed at $30^{\circ} \mathrm{C}$ in $50 \mathrm{mM}-\mathrm{Tris} / \mathrm{H}_{2} \mathrm{SO}_{4}$ buffer, $\mathrm{pH} 7.5$, containing $5 \mathrm{~mm}$ substrate and crude extract in a final volume of $3 \mathrm{ml}$. At different times within $25 \mathrm{~min}$ the epoxide concentration was analysed by gas chromatography. Chemical hydrolysis of the epoxides was negligible under these conditions. One unit of epoxide hydrolase was defined as the activity that catalyses the degradation of $1 \mu \mathrm{mol}$ of epoxide $\min ^{-1}$.

For the identification of the products formed during conversion of halohydrins and epoxides in crude extracts, assays were run in a final volume of $0.5 \mathrm{ml}$ in $1.5 \mathrm{ml}$ vials, which were closed gas-tight with Teflon-lined caps. Samples were taken within $30 \mathrm{~min}$ and analysed by gas chromatography-mass spectrometry (GC-MS). In the case of less stable substrates, such as 1,3-dibromo-2-propanol, 1,3-dichloroacetone and 1-bromo-2-propanol, assay mixtures were incubated for $10 \mathrm{~min}$, after which the products were analysed immediately.

Oxygen consumption by crude extracts was measured at $30^{\circ} \mathrm{C}$ with a Clark-type oxygen electrode. Protein was determined by the method of Lowry using bovine serum albumin as the standard. 
Gas chromatography. Epichlorohydrin was quantitatively determined by capillary gas chromatography. Equipment and the temperature program were as previously described (Janssen et al., 1987). Culture samples $(3 \mathrm{ml})$ were extracted with $1 \mathrm{ml}$ diethylether containing $1 \mathrm{~mm}$-trichloroethylene as internal standard and the ether layer was analysed by split injection of $1 \mu \mathrm{l}$ samples in the gas chromatograph. Other epoxides and halohydrins were quantified similarly.

Diols were analysed by direct split injection of $0.02 \mu$ laqueous samples. A CPsil5-CB column $(25 \mathrm{~m} \times 0.22 \mathrm{~mm}$; Chrompack), was used with helium $\left(110 \mathrm{kPa}\right.$, vent flow $\left.30 \mathrm{ml} \mathrm{min}^{-1}\right)$ as the carrier gas. Quantitative analysis of 3-chloro-1,2-propanediol was done in the same way, but the sample was mixed with an equal volume of water containing $1.0 \mathrm{~mm}-1,2$-propanediol as the internal standard, before injection. Further conditions and detection were as for epichlorohydrin analysis.

Mass spectrometry. Aqueous solutions of 1,3-dichloro-2-propanol, 1-chloro-2-propanol, 3-chloro-1,2-propanediol, chloroacetone, 1,3-dichloroacetone, 1,3-dibromo-2-propanol, epibromohydrin, glycidol (3-hydroxy1,2-epoxypropane), propylene oxide (1,2-epoxypropane), 1,2-propanediol, hydroxyacetone and epichlorohydrin were analysed by GC-MS. The instrument used was a Ribermag R10-10C, operated at an electron beam energy of $70 \mathrm{eV}$ and a source temperature of $180^{\circ} \mathrm{C}$. Water samples $(0.5 \mu \mathrm{l})$ containing $1-3 \mathrm{mM}$ concentrations of compounds to be analysed were injected without extraction on a CPsil5-CB column $(25 \mathrm{~m} \times 0.35 \mathrm{~mm})$ with helium as carrier gas $(150 \mathrm{kPa})$. The temperature program used was $3 \mathrm{~min}$ at $50^{\circ} \mathrm{C}$ followed by $10^{\circ} \mathrm{C} \mathrm{min}^{-1}$ to $250^{\circ} \mathrm{C}$.

Chemicals. All organic compounds used were obtained from commercial sources (Janssen Chimica or Aldrich) and were at least $95 \%$ pure, as checked by gas chromatography and NMR spectroscopy. Exceptions were 1-chloro2-propanol and 1-bromo-2-propanol, which contained about 20\% 2-chloro-1-propanol and 2-bromo-1-propanol, respectively.

\section{RESULTS}

\section{Characterization of strains $A D 1, A D 2$ and $A D 3$}

Three different bacterial cultures capable of growing with epichlorohydrin as sole source of carbon and energy were isolated from polluted freshwater sediment. The characteristics of strain AD1 (Table 1) suggested that this bacterium might belong to the genus Pseudomonas (Palleroni, 1984). Strain AD2 was tentatively identified as a strain of Arthrobacter (Keddie et al., 1986) (Table 1). The bacterium appeared as coccoid cells, often in pairs, which in complex media underwent a marked change to irregular rods with post-fission outgrowths. Cells became coccoid in stationary cultures. Strain AD3 was a Gram-positive non-sporing curved rod, or coryneform bacterium (Jones \& Collins, 1986) (Table 1). The organism often appeared as single cells but also formed pairs or short chains.

All three strains were able to grow on glycerol, glycidol or glucose, but not on propylene oxide, 1,2-propanediol, ethylene glycol, hydroxyacetone or methanol.

\section{Utilization of halogenated compounds}

The utilization of halogenated compounds other than epichlorohydrin by strains AD1, AD2 and AD3 was determined. Growth tests were done in liquid medium supplemented with different halogenated substrates at a concentration of $4 \mathrm{~mm}$ (Table 2).

The three strains were able to grow on epichlorohydrin and 3-chloro-1,2-propanediol. Strain AD2 and strain AD3 showed slow growth on 1,3-dichloro-2-propanol and were not able to degrade this compound completely within $6 \mathrm{~d}$. In contrast, strain AD1 grew with a generation time of $3.3 \mathrm{~h}$ on 1,3-dichloro-2-propanol and utilized this compound completely. In all cases, growth was accompanied by halide release which strongly exceeded uninoculated controls. No growth was observed with all three strains on chloroacetic acid, 3-chloropropionic acid, 2-chloropropionic acid, 1,3-dichloropropane, 1,3-dichloropropene, 3-chloropropene, 1-chloro2-propanol, chloroacetone, 1,3-dichloroacetone, 2-chloro-3-butanone, 1,2-dichloropropane, 2-chloroethanol, 2-bromoethanol and 1,3-dibromo-2-propanol.

\section{Degradation of epichlorohydrin in batch cultures}

Growth of strains AD1 and AD3 on 5 mM-epichlorohydrin was followed in batch cultures (Fig. $1 a, b$ ). Almost immediately after inoculation, there was a fast decrease of the epichlorohydrin concentration resulting in a complete depletion of the compound in the lag phase. No significant chloride production occurred during this phase of rapid epichlorohydrin 
Table 1. Some properties of the epichlorohydrin-utilizing bacterial strains AD1, AD2 and AD3

$\quad$ Property
Gram reaction
Acid-fast staining
Oxidase
Catalase
Nitrate reduction
Fermentation
Endospores formed
Flagellation
Growth at $37^{\circ} \mathrm{C}$
Morphology
Motility
Pigmentation
Colony morphology
Length $(\mu \mathrm{m})$
Width $(\mu \mathrm{m})$

Strain AD1
Negative
ND
+
+
+
-
-
$+*$
ND
Rod
+
None
Circular, convex,
entire, translucent
$2.0-3.0$
$0.8-1.0$
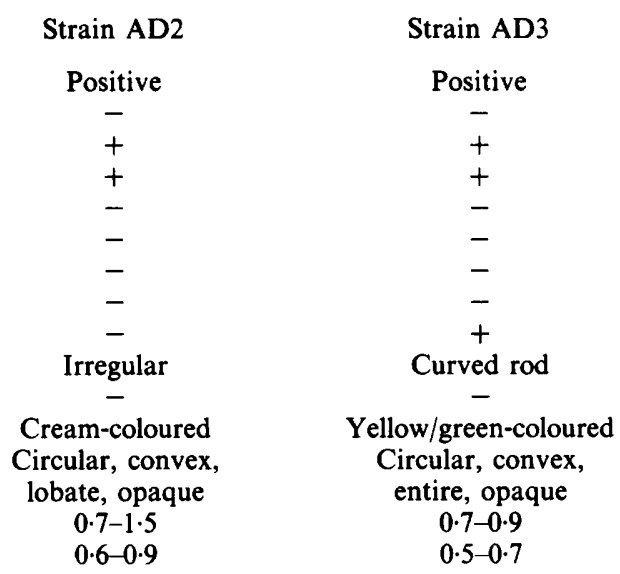

ND, Not determined.

* One polar flagellum visible by electron microscopy.

+ Cells were grown in MMY-medium containing 5 mM-glucose.

Table 2. Utilization of halogenated compounds by strains AD1, AD2 and AD3

Carbon sources were added to a final concentration of $4 \mathrm{~mm}$. Precultures were grown on 4 mM-epichlorohydrin.

\begin{tabular}{|c|c|c|c|c|c|c|}
\hline \multirow[b]{2}{*}{ Carbon source } & \multicolumn{2}{|c|}{$\begin{array}{l}\text { Generation time } \\
\text { (h) }\end{array}$} & \multicolumn{4}{|c|}{ Halide produced (mM)* } \\
\hline & AD1 & AD3 & AD1 & $\mathrm{AD} 2$ & AD3 & Sterile control \\
\hline $\begin{array}{l}\text { Epichlorohydrin } \\
\text { 1,3-Dichloro-2-propanol } \\
\text { 3-Chloro-1,2-propanediol }\end{array}$ & $\begin{array}{l}5 \cdot 5 \\
3 \cdot 3 \\
3 \cdot 1\end{array}$ & $\begin{array}{c}14 \cdot 0 \\
- \\
10 \cdot 5\end{array}$ & $\begin{array}{l}4 \cdot 2 \\
7 \cdot 9 \\
4 \cdot 2\end{array}$ & $\begin{array}{l}3 \cdot 4 \\
4 \cdot 7 \\
3 \cdot 9\end{array}$ & $\begin{array}{l}4 \cdot 2 \\
3 \cdot 2 \\
3 \cdot 6\end{array}$ & $\begin{array}{l}0 \cdot 2 \\
1 \cdot 2 \\
0 \cdot 3\end{array}$ \\
\hline
\end{tabular}

turnover. The conversion of epichlorohydrin was due to a high enzymic activity since its concentration decreased much more slowly in sterile controls (Fig. 1d).

The accumulating halogenated compound in cultures of ADl and AD3 was identified by GC-MS as 3-chloro-1,2-propanediol, which is in agreement with the absence of chloride production during epichlorohydrin degradation. The halohydrin was also identified in the culture fluids of a mutant of strain AD1 lacking dehalogenase activity (see below). 3-Chloro1,2-propanediol was stable in sterile medium, showing no significant chloride release (Table 2). Both strains AD1 and AD3 were able to utilize this compound as a carbon source and actively degraded epichlorohydrin. The growth rates on epichlorohydrin (Table 2) may thus be determined by the rate of metabolism of 3-chloro-1,2-propanediol. The growth of strain AD1 was much faster than that of strain AD3 for the three halogenated compounds mentioned in Table 2 and therefore we chose strain AD1 for further study.

The decrease of epichlorohydrin concentration in a batch culture of strain AD2 (Fig. 1c) proceeded at a rate similar to the sterile control (Fig. 1d). Epichlorohydrin was slowly converted with a half-life of about $70 \mathrm{~h}$, in agreement with earlier findings of Ross (1950). This suggests that in contrast to strains AD1 and AD3, strain AD2 was not capable of active degradation of epichlorohydrin but merely utilized the product of chemical hydrolysis, 3-chloro-1,2-propanediol. Also, strain AD2 showed non-exponential growth with 3-chloro-1,2-propanediol and 1,3-dichloro-2-propanol, the latter compound being only partially degraded. 

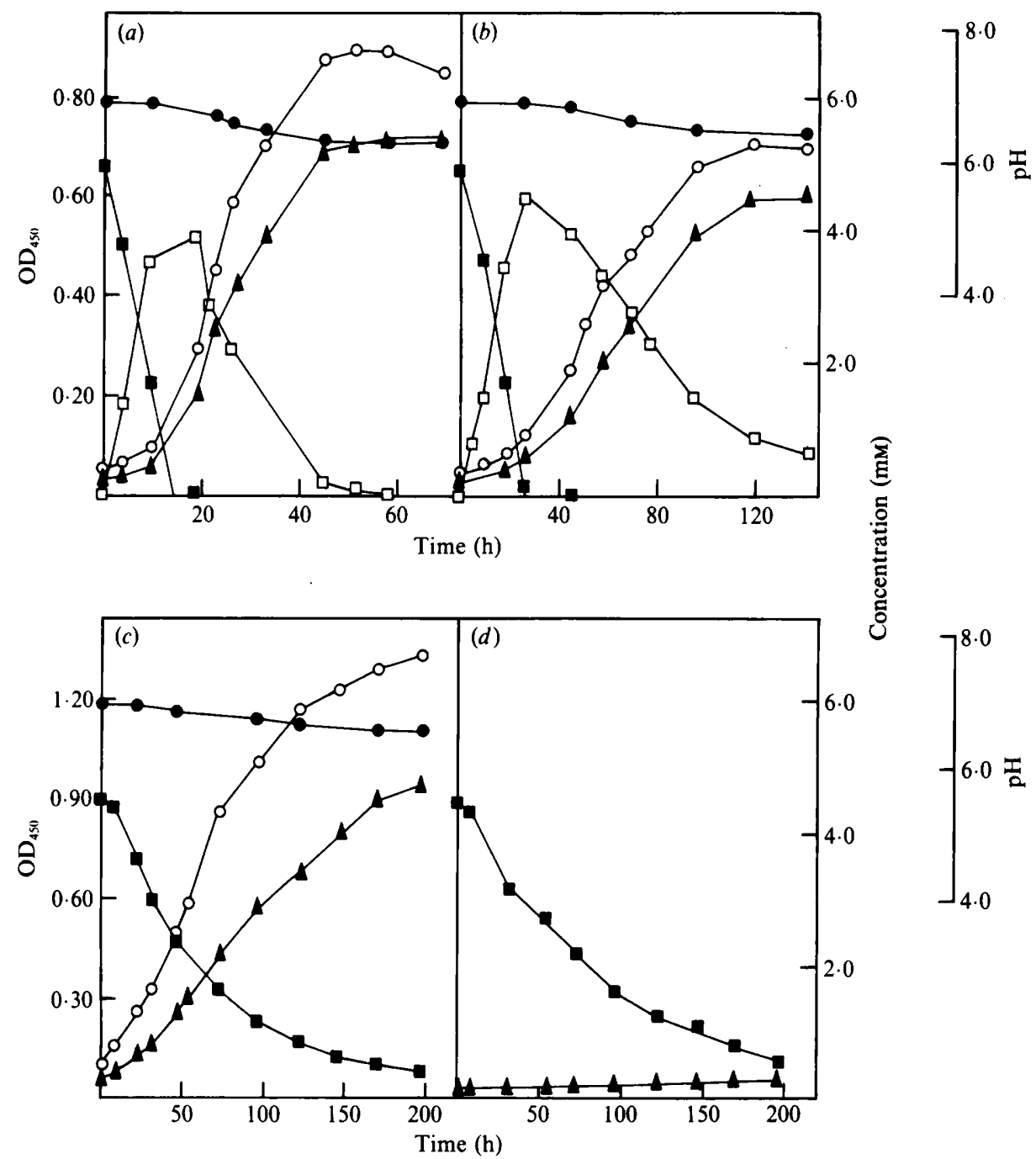

Fig. 1. Batch cultures on 5 mm-epichlorohydrin of strains AD1 (a), AD3 (b) and AD2 (c). (d) Sterile control. $\mathrm{O}, \mathrm{OD}_{450} ; \boldsymbol{\Lambda}$, chloride; $\boldsymbol{\square}$, epichlorohydrin; $\square, 3$-chloro-1,2-propanediol; $\bullet$, pH.

Because of the inability of strain AD2 to actively degrade epichlorohydrin to 3-chloro1,2-propanediol, we decided to compare the properties of this strain in more detail with the epichlorohydrin-utilizing strain AD1.

\section{Degradation of epoxides by crude extracts}

The rapid transient accumulation of 3-chloro-1,2-propanediol observed in cultures of strain ADl suggests that this bacterium produces an epoxide hydrolase activity toward epichlorohydrin. Therefore, crude extracts were prepared from epichlorohydrin-grown cells and incubated with several epoxides (Table 3). The rate of epoxide degradation was highest with propylene oxide, but epibromohydrin and epichlorohydrin were also rapidly converted.

The epoxidase activity was present in extracts of citrate- or glucose-grown cultures of strain ADl at levels of 59 and $137 \mathrm{mU}$ (mg protein $)^{-1}$, respectively, which is lower than the activity in cells from epichlorohydrin-grown cultures (Table 3). Glycidol-grown cells of strain AD1 contained $817 \mathrm{mU}$ (mg protein $)^{-1}$ of epoxide-degrading activity, showing that the formation of this activity is inducible. 
Table 3. Epoxide hydrolase activities towards various substrates in crude extracts of strains ADI and AD2 grown on epichlorohydrin

\begin{tabular}{clr} 
Strain & \multicolumn{1}{c}{ Substrate } & \multicolumn{2}{c}{ Specific act } \\
[mU (mg pro
\end{tabular}

Table 4. Dehalogenating activities towards various substrates in crude extracts of strains AD1, $A D 1 M 12$ and $A D 2$ grown on epichlorohydrin or on citrate

\begin{tabular}{|c|c|c|c|c|c|}
\hline \multirow[b]{3}{*}{ Substrate } & \multicolumn{5}{|c|}{ Specific activity [mU (mg protein $\left.)^{-1}\right]$} \\
\hline & \multicolumn{2}{|c|}{ Epichlorohydrin } & \multicolumn{3}{|c|}{ Citrate } \\
\hline & ADl & AD2 & $\mathrm{AD} 1$ & AD1M12* & $\mathrm{AD} 2$ \\
\hline 1,3-Dichloro-2-propanol & 287 & 870 & 22 & $<4$ & 38 \\
\hline 1-Chloro-2-propanol & 260 & 178 & 13 & $<4$ & 8 \\
\hline 3-Chloro-1,2-propanediol & 20 & 167 & - & - & - \\
\hline 1,3-Dibromo-2-propanol & 5022 & 117000 & 297 & $<4$ & 9268 \\
\hline 1-Bromo-2-propanol & 1109 & 30070 & 63 & $<4$ & 1220 \\
\hline 1,3-Dichloroacetone & 337 & 2159 & 24 & $<4$ & 141 \\
\hline Chloroacetone & 87 & 113 & - & - & - \\
\hline Epichlorohydrin & $<10$ & $<4$ & - & - & - \\
\hline Chloroacetic acid & $<10$ & $<4$ & - & - & - \\
\hline 2-Bromoethanol & 109 & 691 & - & - & - \\
\hline
\end{tabular}

Crude extracts of strain AD2 grown on epichlorohydrin, in contrast, did not actively convert epichlorohydrin (Table 3). This conversion was also not found in batch cultures of strain AD2 grown on epichlorohydrin (Fig. 1), indicating that strain AD2 does not produce an epichlorohydrin epoxide hydrolase.

\section{Dehalogenations catalysed by crude extracts of strains $A D 1$ and $A D 2$}

The dehalogenation capacities of strains AD1 and AD2 were investigated by incubating various halogenated compounds with crude extracts prepared from cells of late exponential cultures grown on 5 mM-epichlorohydrin or on $5 \mathrm{~mm}$-citrate (Table 4). Strain AD1 showed very little dehalogenating activity and strain AD2 showed no activity at all with epichlorohydrin. Halide release in crude extracts of strains AD1 and AD2 was observed with halohydrins such as 1,3-dichloro-2-propanol, 1-chloro-2-propanol, 3-chloro-1,2-propanediol, 1,3-dibromo-2propanol and 1-bromo-2-propanol. Halide production was also found with chloroacetone and 1,3-dichloroacetone. No activity of strains AD1 and AD2 was found with 2-chloropropionic acid, 1,3-dichloropropane, 1,3-dichloropropene, 1-chloropropane, 2-chloropropane, 1,2-dichloropropane, 1-bromo-3-propanol, 2-chloro-1-propanol, 2-bromo-1-propanol, 1,2-dichloroethane, 1-chlorobutane and 2-chloro-3-butanone. The dehalogenating systems had different relative activities for the halogenated compounds tested, which indicates that the enzymes involved probably are not identical.

The dehalogenating activities were due to enzymic conversion since heat treatment of crude extracts of strains $\mathrm{AD} 1$ and $\mathrm{AD} 2\left(5 \mathrm{~min}\right.$ at $\left.100^{\circ} \mathrm{C}\right)$ resulted in complete disappearance of activity with 1,3-dichloro-2-propanol, 1,3-dibromo-2-propanol and 1,3-dichloroacetone as substrates. None of the dehalogenating enzymes needed oxygen or cofactors for activity. During 
Table 5. Products formed in crude extracts of strains AD1 and AD2 grown on epichlorohydrin

\begin{tabular}{|c|c|c|}
\hline \multirow[b]{2}{*}{ Substrate } & \multicolumn{2}{|c|}{ Products found } \\
\hline & Strain AD1 & Strain AD2 \\
\hline $\begin{array}{l}\text { 1,3-Dichloro-2-propanol } \\
\text { 1-Chloro-2-propanol } \\
\text { 3-Chloro-1,2-propanediol }\end{array}$ & $\begin{array}{l}\text { 3-Chloro-1,2-propanediol } \\
\text { 1,2-Propanediol } \\
*\end{array}$ & $\begin{array}{l}\text { Epichlorohydrin } \\
\text { Propylene oxide } \\
\text { Glycidol }\end{array}$ \\
\hline $\begin{array}{l}\text { Epichlorohydrin } \\
\text { Chloroacetone }\end{array}$ & $\begin{array}{l}\text { 3-Chloro-1,2-propanediol } \\
\text { Hydroxyacetone }\end{array}$ & $\begin{array}{l}\text { No conversion } \\
\text { Hydroxyacetone }\end{array}$ \\
\hline 1,3-Dibromo-2-propanol & $\begin{array}{l}\text { Epibromohydrin, } \\
\text { 3-bromo-1,2-propanediol }\end{array}$ & Epibromohydrin \\
\hline $\begin{array}{l}\text { Epibromohydrin } \\
\text { 1-Bromo-2-propanol }\end{array}$ & $\begin{array}{l}\text { 3-Bromo-1,2-propanediol } \\
\text { Propylene oxide, } \\
\text { 1,2-propanediol }\end{array}$ & $\begin{array}{l}\text { No conversion } \\
\text { Propylene oxide }\end{array}$ \\
\hline Propylene oxide & 1,2-Propanediol & No conversion \\
\hline
\end{tabular}

* No product found by GC-MS.

conversion of 2 mM-1,3-dichloro-2-propanol by crude extracts of strains AD1 and AD2 in a biological oxygen monitor, no oxygen consumption was detectable.

Crude extracts of strain AD1 grown on citrate possessed 5-10\% activity for halohydrins compared to extract from epichlorohydrin-grown cells, indicating that the dehalogenating enzyme is largely inducible by epichlorohydrin. This appeared to be the same with strain AD2 (Table 4).

\section{Isolation of an epichlorohydrin-negative mutant of strain ADI}

To obtain further insight into the enzymic conversion of epichlorohydrin, a mutant of strain ADl was isolated after several serial transfers in MMY-medium with 5 mM-glycidol (see Methods). The mutant, designated strain AD1M12, had lost both its capacity to grow on epichlorohydrin and 3-chloro-1,2-propanediol but not on glycidol. Furthermore, no dehalogenating activity was detected in cells grown on citrate (Table 4). This was due to mutational loss of the dehalogenating enzyme, since strain ADl grown on citrate still possessed activity for halohydrins.

To discriminate between a possible epoxide hydrolase and the dehalogenating enzyme of strain ADl, $30 \mathrm{~mm}$-epichlorohydrin was added to a $3 \mathrm{~mm}$-glycidol-grown culture of mutant AD1M12. After $16 \mathrm{~h}$ no epichlorohydrin was left and there was also no increase in chloride concentration. The accumulated intermediate was analysed by GC-MS and found to be 3-chloro-1,2-propanediol. Since the formation of this diol and the depletion of epichlorohydrin were much faster than could possibly be accomplished by chemical hydrolysis (Fig. $1 d$; Ross, 1950), it was concluded that uptake was not affected and that conversion of epichlorohydrin to 3-chloro-1,2-propanediol was due to an epoxide hydrolase, which is different from the dehalogenating enzyme and still present in the mutant.

\section{Products formed in crude extracts}

The products formed during incubation of halohydrins and epoxides with crude extracts prepared from cells of strains AD1 and AD2 grown on epichlorohydrin were analysed by GC-MS. Extracts of strain ADl converted epichlorohydrin, epibromohydrin and propylene oxide to their corresponding diols (Table 5), again showing the presence of an epoxide hydrolase activity involved in epichlorohydrin metabolism (Fig. 2).

Extracts of strain ADl as well of strain AD2 catalysed dehalogenation of halohydrins (Table 4). The mode of action of the dehalogenating systems was indicated by the conversion of 1,3-dibromo-2-propanol to epibromohydrin and 1-bromo-2-propanol to propylene oxide (Table 5 ). Dehalogenation thus occurred with concomitant production of an epoxide, indicating the 


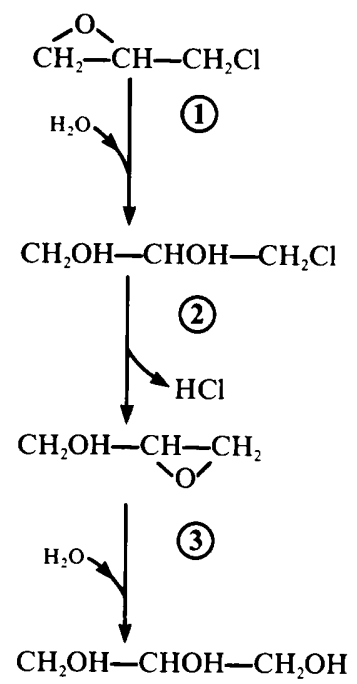

Fig. 2. Proposed routes for the degradation of epichlorohydrin. Strain AD1: epoxide hydrolase (1), halohydrin dehalogenase (2) and epoxide hydrolase (3). Strain AD2: chemical conversion (1), halohydrin dehalogenase (2) and chemical conversion (3).

action of an epoxide-forming halohydrin dehalogenase (Fig. 2). Prolonged incubation ( $30 \mathrm{~min})$ of extracts of strain AD1 with these bromohydrins yielded also 3-bromo-1,2-propanediol and 1,2-propanediol.

With crude extract of strain AD2, epoxides were identified as the sole products formed from 1,3-dichloro-2-propanol, 3-chloro-1,2-propanediol and 1-chloro-2-propanol.

Upon incubation with extract from strain AD1, however, the corresponding diols rather than epoxides were produced from 1,3-dichloro-2-propanol and 1-chloro-2-propanol. Under the assay conditions used, the rates of epoxide hydrolysis of epichlorohydrin and propylene oxide are much higher than the rate of formation of these compounds from vicinal chlorohydrins by dehalogenase activity (Tables 3 and 4). Only when bromohydrins were used as the substrates for extract of strain AD1 were epoxides detected. The activity of the dehalogenase for these bromohydrins was much higher than for chlorohydrins (Table 4). With extract of strain AD1, no epoxide product was found with 3-chloro-1,2-propanediol, again probably due to the interference of the epoxide hydrolase (Table 3).

\section{DISCUSSION}

The results presented in this paper show that epichlorohydrin and several related halohydrins may serve as sole carbon source for bacterial growth. Although growth on vicinal halohydrins has been found previously (Castro \& Bartnicki, 1968; Stucki \& Leisinger, 1983; Janssen et al., 1985), growth on epichlorohydrin had not been reported (Krijgsheld \& van der Gen, 1986).

Two patterns of epichlorohydrin degradation were observed in batch cultures. Strain AD1, a Pseudomonas-like organism, and the coryneform bacterium strain AD3, rapidly degraded epichlorohydrin in the lag phase of growth to 3-chloro-1,2-propanediol and then utilized this compound. Strain AD2, on the other hand, was not capable of active utilization of epichlorohydrin but only metabolized 3-chloro-1,2-propanediol produced by chemical degradation.

In strain AD1, epichlorohydrin degradation apparently started with an epoxide hydrolase reaction producing a diol rather than with a hydrolytic dehalogenation leading to glycidol (Fig. 2). With crude extracts and purified dehalogenase of Xanthobacter autotrophicus GJ10, which is 
able to utilize 1,2-dichloroethane (Janssen et al., 1985; Keuning et al., 1985), we have found chloride release with epichlorohydrin as the substrate at $12 \%$ of the rate found with 1,2-dichloroethane. Thus, as an alternative, conversion of epichlorohydrin to glycidol as the first step of epichlorohydrin degradation would theoretically be possible, but this route does not appear to be of importance in the organisms described here.

The epoxide hydrolase of strain AD1 probably has a broad substrate range, catalysing the hydrolysis of epichlorohydrin, epibromohydrin, glycidol and propylene oxide. No conversion of these compounds was found in extracts of strain AD2 and the lack of active epichlorohydrin utilization in this strain thus appeared to be caused by the absence of epoxide hydrolase activity. Thus growth of strain AD2 with epichlorohydrin as carbon source will be limited by the rate of chemical hydrolysis of epichlorohydrin. Ross (1950) examined the kinetics of epoxide-ring opening reactions and found a rate constant of $0.019 \mathrm{~h}^{-1}$ for epichlorohydrin hydrolysis at $37^{\circ} \mathrm{C}$ and neutral $\mathrm{pH}$, which is of the same order of magnitude as the half-life of $70 \mathrm{~h}$ at $30^{\circ} \mathrm{C}$ found here.

Hydrolysis of the epoxide ring as a first step in epichlorohydrin conversion has also been found in rats (Fakhouri \& Jones, 1979; Jones \& Fakhouri, 1979). As an alternative, epichlorohydrin may be metabolized via glutathione conjugation, which finally yields 2,3-dihydroxy-1-S-propylcysteine and its $N$-acetyl derivative, the major metabolites found in urine (Fakhouri \& Jones, 1979; Jones \& Fakhouri, 1979).

Information about bacterial epoxide hydrolase activity is scarce. One of the few descriptions of this enzyme concerns a propylene-oxide-utilizing Nocardia which produces an inducible epoxidase activity that catalyses the conversion of propylene oxide to 1,2-propanediol (de Bont et al., 1982). More details on the regulation and properties of the epoxide hydrolase of strain AD1 will be reported elsewhere.

The actual substrates for the dehalogenating reactions were halohydrins. Halide liberation was found with eight different halohydrins when incubated with crude extracts of strain AD1 or AD2 grown on epichlorohydrin. The relevance of this activity was evident from its inducible character, the cellular levels of the enzyme being strongly elevated during growth with epichlorohydrin, as compared to citrate-grown cultures. Furthermore, a mutant of strain AD2 that had lost the ability to grow with epichlorohydrin no longer formed dehalogenase activity.

Theoretically, the product of the halohydrin dehalogenase reaction could be a diol or an epoxide, the first from a hydrolytic reaction and the second from an intramolecular substitution. Analysis of products formed in crude extracts of strain AD2 by GC-MS revealed that epoxides were produced from all five halohydrins tested. With strain AD1, epoxides were also found but not when chlorohydrins were added as substrates. The diols found as products in this case are considered to be due to further conversion by the epoxide hydrolase that is present in this organism. Dehalogenation of 3-chloro-1,2-propanediol to form glycidol has also been observed in rats (Jones, 1975). The latter compound may either undergo conjugation with liver glutathione to produce 2,3-dihydroxy-1-S-propylcysteine (Bray et al., 1969; Jones \& Fakhouri, 1979) or can be hydrolysed to glycerol (Jones, 1975).

Different routes for channelling epoxides in intermediary metabolism have been found (Weijers et al., 1988). In incubations with extracts of strain AD1, but not of AD2, glycidol was converted, suggesting a role for the epoxide hydrolase, but no attempt was made to identify the product. Hydrolysis of glycidol to glycerol has been described (Bartnicki \& Castro, 1969). Glycidol is hydrolysed at a lower rate than epichlorohydrin (Ross, 1950) probably making enzymic conversion necessary for growth.

The above mechanism for dehalogenation has also been observed with partially purified halohydrin epoxidase of a Flavobacterium sp. utilizing 2,3-dibromo-1-propanol (Castro \& Bartnicki, 1968; Bartnicki \& Castro, 1969). Both the enzyme described there and the dehalogenases identified in this paper have a very high activity for brominated vicinal alcohols. Since the relative dehalogenase activities of strain AD1, strain AD2 and the Flavobacterium sp. for chlorohydrins and bromohydrins are different, it is probable that the enzymes of the three organisms are not identical proteins.

Another striking difference between the activities identified here and the Flavobacterium 
enzyme was the activity towards mono- and dichlorinated ketones of the halohydrin dehalogenases found in strains AD1 and AD2. It is unlikely that the organisms produce different dehalogenating enzymes for halohydrins and haloketones since the relative activities of extracts for the chloroacetones and halohydrins were the same in citrate- and epichlorohydrin-grown cells. Moreover, the epichlorohydrin-negative mutant AD1M12 had lost its activity for chlorinated ketones, which makes the involvement of different dehalogenating enzymes in strain AD1 improbable. It remains to be determined whether the halohydrin dehalogenases catalyse conversion of haloketones by using water as a nucleophile or use an enol tautomer as the actual substrate for an intramolecular substitution.

Further studies will involve kinetic aspects of epichlorohydrin and halohydrin degradation that are relevant for the application of epichlorohydrin-degrading organisms in treatment systems for the removal of these toxic compounds from waste streams.

This work was financed in part by a grant from the Dutch Ministry of Housing, Physical Planning and Environment. The work of D. B. J. has been made possible by a fellowship from the Royal Netherlands Academy of Sciences. The authors thank A. Kiewiet for performing the GC-MS analyses.

\section{REFERENCES}

BARTNICKI, E. W. \& Castro, C. E. (1969). Biodehalogenation. The pathway for transhalogenation and the stereochemistry of epoxide formation from halohydrins. Biochemistry 8, 4677-4680.

BERGMANN, J. G. \& SANIK, J. (1957). Determination of trace amounts of chlorine in naphtha. Analytical Chemistry 29, 241-243.

DE Bont, J. A. M., van Dijken, J. P. \& van Ginkel, K. G. (1982). The metabolism of 1,2-propanediol by the propyleneoxide utilizing bacterium Nocardia A60. Biochimica et biophysica acta 714, 465-470.

Bray, H. G., Garrett, A. J. \& JAmes, S. P. (1969). Some observations on the source for mercapturic acid formation. Biochemical Pharmacology 18, 1203 1206.

Castro, C. E. \& Bartnicki, E. W. (1968). Biodehalogenation. Epoxidation of halohydrins, epoxide opening, and transhalogenation by a Flavobacterium sp. Biochemistry 7, 3213-3218.

GHISALBA, O. (1983). Chemical wastes and their biodegradation - an overview. Experientia 39, 12471257.

FAKHoURI, G. \& JoNES, A. R. (1979). Epi-chlorohydrin: metabolism and toxicity in the rat. Australian Journal of Pharmaceutical Sciences 8, 1114.

Janssen, D. B., Scheper, A., Dijkhuizen, L. \& WitholT, B. (1985). Degradation of halogenated aliphatic compounds by Xanthobacter autotrophicus GJ10. Applied and Environmental Microbiology 49, 673-677.

JANSSEN, D. B., JAGER, D. \& WitholT, B. (1987). Degradation of $n$-haloalkanes and $\alpha$ - $\omega$-dihaloalkanes by wild-type and mutants of Acinetobacter sp. strain GJ70. Applied and Environmental Microbiology 53, 561-566.

Janssen, D. B., Gerritse, J., Brackman, J., Kalk, C., JAGER, D. \& Witholt, B. (1988). Purification and characterization of a bacterial dehalogenase with activity toward halogenated alkanes, alcohols and ethers. European Journal of Biochemistry 171, 67-72.
JONES, A. R. (1975). The metabolism of 3-chloro-, 3-bromo- and 3-iodopropan-1,2-diol in rats and mice. Xenobiotica 5, 155-165.

JONES, D. \& Collins, M. D. (1986). Irregular, nonsporing Gram-positive rods. In Bergey's Manual of Systematic Bacteriology, vol. 2, pp. 1261-1266. Edited by P. H. A. Sneath. Baltimore: Williams \& Wilkins.

JoNES, A. R. \& FAKhouri, G. (1979). Epoxides as obligatory intermediates in the metabolism of $\alpha$-halohydrins. Xenobiotica 9, 595-599.

Keddie, R. D., Collins, M. D. \& Jones, D. (1986). Genus Arthrobacter. In Bergey's Manual of Systematic Bacteriology, vol. 2, pp. 1288-1301. Edited by P. H. A. Sneath. Baltimore: Williams \& Wilkins.

Keuning, S., Janssen, D. B. \& Witholt, B. (1985). Purification and characterization of hydrolytic haloalkane dehalogenase from Xanthobacter autotrophicus GJ10. Journal of Bacteriology 163, 635-639.

KRIJGSHELD, K. R. \& VAN DER GEN, A. (1986). Assessment of the impact of the emission of certain organochlorine compounds on the aquatic environment. 3. Epichlorohydrin. Chemosphere 15, 881-893.

Palleroni, N. J. (1984). Genus Pseudomonas. In Bergey's Manual of Systematic Bacteriology, vol. 1, pp. 141-199. Edited by N. R. Krieg. Baltimore: Williams \& Wilkins.

Ross, W. C. J. (1950). The reactions of certain epoxides in aqueous solutions. Journal of the Chemical Society, 2257-2272.

STUCKI, G. \& LeISINGER, T. (1983). Bacterial degradation of 2-chloroethanol proceeds via chloroacetic acid. FEMS Microbiology Letters 16, 123-126.

Vogel, T. M., Criddle, C. S. \& McCarty, P. L. (1987). Transformations of halogenated aliphatic compounds. Environmental Science and Technology 21, 722-736.

Weijers, C. A. G. M., DE HaAn, A. \& De Bont, J. A. M. (1988). Microbial production and metabolism of epoxides. Microbiological Sciences 5, 156159. 